\title{
A PERCEPÇÃO DOS DOCENTES DE DISCIPLINAS CONTÁBEIS ACERCA DO ENSINO DE CONTABILIDADE PARA DISCENTES DO CURSO DE ENGENHARIA DE PRODUÇÃO ${ }^{1}$
}

\section{THE ACCOUNTING PROFESSORS' PERCEPTION ABOUT ACCOUNTING EDUCATION FOR STUDENTS OF THE MANUFACTURING ENGINEERING COURSE}

\section{Thiago Cunha de Oliveira}

Mestre em Ciências Contábeis pelo Programa de Pós-Graduação em Ciências Contábeis da

Universidade Federal do Rio de Janeiro - PPGCC/UFRJ

thiaguhc@gmail.com

\section{Rosana Pinho Galiza}

Mestre em Ciências Contábeis pelo Programa de Pós-Graduação em Ciências Contábeis da

Universidade Federal do Rio de Janeiro - PPGCC/UFRJ

pinhors@yahoo.com.br

Fabiano Rosa Lamoglia

Mestre em Ciências Contábeis pelo Programa de Pós-Graduação em Ciências Contábeis da Universidade Federal do Rio de Janeiro - PPGCC/UFRJ

fabiano@lamoglia.com.br

\section{Márcia da Silva Carvalho}

Doutora em Planejamento Ambiental COPPE/UFRJ

Universidade Federal do Rio de Janeiro

marcia@facc.ufri.br

\section{RESUMO}

Objetivo: Analisar as percepções dos docentes de contabilidade que atuam na graduação em Engenharia de Produção, a fim de identificar as variáveis que impactam no processo de ensinoaprendizagem do discente no que tange às disciplinas da área contábil.

Fundamento: $\mathrm{O}$ processo de ensino-aprendizagem por parte de docentes de contabilidade que atuam em outros cursos deve ser realizado diferentemente do aplicado aos discentes de contabilidade (Tan \& Laswad, 2006), mostrando-se uma temática relevante para a formação de um profissional que cada vez mais necessita da interdisciplinaridade em sua formação, o engenheiro de produção.

\footnotetext{
${ }^{1}$ Artigo recebido em: 27/04/2019. Revisado por pares em: 12/08/2019. Reformulado em: 31/10/2019. Recomendado para publicação: 27/11/2019 por Adriana Fernandes de Vasconcelos (Editora Chefe). Publicado em: 01/05/2020. Organização responsável pelo periódico: UFPB
} 
Método: A coleta de dados consistiu em entrevistas semiestruturadas realizadas com quatro docentes de contabilidade que atuam no curso de Engenharia de Produção em uma Instituição de Ensino Superior Federal localizada na cidade do Rio de Janeiro, sendo os dados coletados e analisados a partir da técnica de Análise de Conteúdo.

Resultados: As dificuldades no processo de ensino-aprendizagem estão relacionadas ao não entendimento da relevância das disciplinas contábeis por parte dos discentes e, ainda, sua baixa carga-horária. Contudo, os docentes entrevistados entendem que a presença de disciplinas contábeis é relevante para a formação dos discentes e, ainda, que o fato de o perfil destes ser mais voltado para a ciência matemática facilita o ensino de questões pertinentes à seara contábil.

Contribuições: Explicitou-se as variáveis que impactam no ensino de disciplinas contábeis no curso de Engenharia de Produção, possibilitando que tais fatores possam ser melhor analisados pelos sujeitos envolvidos no processo de ensino-aprendizagem e, assim, tal prática de ensino possa ser aperfeiçoada.

Palavras-chave: Interdisciplinaridade. Contabilidade. Ensino Contábil. Engenharia de Produção.

\section{ABSTRACT}

Objective: This paper aims to analyse perceptions of accounting professors who teach in undergraduate Manufacturing Engineering course in order to identify variables that impact on the teaching-learning process of the students in regard to the disciplines of the accounting area.

Background: The teaching-learning process by accounting professors who teach in other courses should be carried out differently from that applied to accounting students (Tan \& Laswad, 2006), what demonstrates the relevance of the subject to the education of a professional that demands the interdisciplinarity in their professional education, the production engineer.

Method: The data collection consisted of semi-structured interviews with four accounting professors who teach in the Manufacturing Engineering course in a Federal higher education institution, being the data analyzed by the Content analysis technique.

Results: The difficulties in the teaching-learning process are related to the students' lack of understanding about the accounting disciplines relevance as well as their low hourly load. However, the teachers interviewed understand that the presence of those disciplines is relevant to the education of the students, and also that the students' mathematical profile facilitates the accounting subjects teaching-learning process.

Contributions: It was made explicit the variables which impact the teaching of accounting disciplines in the Manufacturing Engineering course, enabling the people involved to the subject to improve the accounting teaching-learning process.

Keywords: Interdisciplinarity. Accounting. Accounting Teaching. Manufacturing Engineering.

\section{INTRODUÇÃO}

A globalização das empresas, a crescente complexidade das transações comerciais e os avanços na tecnologia da informação, que facilitam o comércio eletrônico e a comunicação, estão desafiando a relevância e a utilidade da educação contábil tradicional (Alhashim \& Weiss, 2004). Todavia, esses fatores não estão limitados apenas à contabilidade, visto que eles também fomentam estudos em outras áreas, criando uma demanda por profissionais de formação multidisciplinar. As pressões exercidas pelo mercado trazem como consequência a necessidade de qualificação da mão de obra. Para Cruz, Batista, Andrade e Bruni (2013), esse cenário obriga as empresas a 
construírem novos modelos de gestão econômico-financeira, demandando uma preparação profissional com articulação conjunta de disciplinas e atividades que possam reunir conteúdos e competências voltadas ao processo de tomada de decisão.

Para Leal e Cornachione Jr. (2006), só o ensino é capaz de formar um cidadão para que este seja capaz de projetar sua própria emancipação político-econômica. Dessa forma, a prática social é antecedida pela formação basilar da escola, que é "o espaço em que o educando pode vivenciar e ter contato com problemas e questões que são elaborados para estimularem seu raciocínio crítico e desenvolver sua criatividade" (Leal \& Cornachione Jr., 2006, p. 92).

Segundo Kraemer (2005), o ensino superior deve avançar para suprir as necessidades e os desafios do mercado, de modo a se adaptar às novas oportunidades, assim como articular-se com as demais instituições sociais e formar cidadãos com potencialidade de desenvolvimento social, cultural, econômico e político. Ainda segundo o autor, "a universidade não pode estar fora ou à parte da sociedade; ela é uma instituição social” (Kraemer, 2005, p. 66). Em um ambiente educacional em que as tendências globais levam os educadores a considerar abordagens alternativas para o ensino e a aprendizagem, novas maneiras devem ser encontradas para educar de forma mais eficiente e efetiva (Wet \& Van Niekerk, 2001).

Discorre Santos (2003) que problemas em Engenharia de Produção (EP) podem ser resolvidos por meio da exploração da interdisciplinaridade dos cursos de EP com áreas correlatas. Tal interdisciplinaridade teria por objetivo oferecer uma formação mais completa e embasada, para que os futuros profissionais consigam lidar com situações desafiadoras, as quais poderão enfrentar na prática laboral.Todavia, para Iudícibus e Marion (2011), poucos são os livros ou materiais básicos com foco no ensino de contabilidade para não contadores, pois grande parte da bibliografia existente na área contábil destina-se a formação do contador, ensinando-o a como fazer a contabilidade. Os autores apontam que o não-contador tem interesse em aprender como entender ou interpretar a contabilidade, logo, o ensino para esses profissionais deveria focar na interpretação dos relatórios contábeis, e não necessariamente no processo de elaboração de demonstrações financeiras.

Para se chegar à melhor decisão, faz-se necessária uma aprimorada interação entre os provedores e os destinatários da informação contábil. A relevância da contabilidade se dá pela comunicação da informação processada e sua interpretação e julgamento. Segundo Tan e Laswad (2006), a comunicação para com os discentes de outras áreas que cursam disciplinas contábeis deve ser realizada de forma distinta ao de estudantes da área contábil, visto que a forma de aprendizado e o contexto acadêmico daqueles podem ser muito diferentes destes.

No que tange ao ensino de contabilidade, especificamente no curso de EP, tanto na Resolução CNE/CES 11, de 11 de março de 2002 (CNE, 2002), atualmente em vigor, quanto na Resolução 2, de 24 de abril de 2019 (ABMES, 2019), a qual passará a ser obrigatória até abril de 2022, não é apontado que em EP as Instituições de Ensino Superior necessitam oferecer disciplinas contábeis; contudo, indica-se a necessidade de, dentre outros conteúdos básicos, aspectos relacionados à Administração e à Economia sejam abordados, nos quais incluem-se, embora não sejam legalmente exigidas, disciplinas contábeis. Diante do exposto, a questão que motiva esta pesquisa é: qual a percepção dos docentes de disciplinas contábeis acerca do ensino de contabilidade para discentes do curso de EP? Assim, o objetivo da pesquisa consiste em identificar estas percepções, a fim de detectar as variáveis que impactam o processo de ensino-aprendizagem do engenheiro de produção no que tange o ensino de disciplinas contábeis.

A fim de cumprir o objetivo proposto, foram realizadas entrevistas presenciais semiestruturadas com docentes de contabilidade de uma instituição federal de ensino localizada na cidade do Rio de Janeiro que ministram disciplinas contábeis para o curso de EP. As respostas obtidas foram analisadas, comparadas e categorizadas, com base na técnica de análise de conteúdo, com auxílio 
do software QSR NVIVO 11, fornecendo material para que o estudo alcançasse o seu objetivo de compreender a importância da temática para o ensino contábil. Este estudo torna-se relevante no sentido de que a contabilidade influencia diretamente o campo empresarial como um todo, haja vista cumprir a função de fornecer informações aos tomadores de decisões de empresas (Silva \& Bruni, 2017). Ainda, não foram encontrados trabalhos que tenham avaliado o tema aventado e, assim, espera-se contribuir para fomentar propostas e posturas metodológicas que auxiliem docentes de disciplinas contábeis na prática da docência no curso de graduação em EP.

Outra contribuição esperada é a de conhecer as facilidades e dificuldades no processo de ensino da contabilidade para discentes do curso de graduação em EP, identificando métodos que mais se adequam ao universo de alunos dessa área, de forma a colaborar com o aperfeiçoamento do processo de ensino-aprendizagem de disciplinas contábeis no âmbito do referido curso.

A presente pesquisa está estruturada em, além desta introdução, referencial teórico abordando: o ensino de contabilidade em EP, o ensino contábil e a interdisciplinaridade. Em seguida, é apresentada a metodologia para a realização da pesquisa. Por fim, a análise de dados, as considerações finais e as referências.

\section{FUNDAMENTAÇÃO TEÓRICA}

\subsection{O Ensino de Contabilidade em Engenharia de Produção}

Em um momento em que o processo de produção de mercadorias necessita de diversificação nos âmbitos de qualidade, quantidade e processo de confecção, o engenheiro, como um funcionário das entidades, passa a ter responsabilidades que excedem a questão do tecnicismo da área, característica dos períodos fordista e taylorista (Nascimento, 2009).

Com relação ao mercado de trabalho em Engenharia, cada vez mais acirrado e exigindo diferenciais por parte de seus profissionais, o funcionário que souber trabalhar em equipe e possuir conhecimentos interdisciplinares terá maiores possibilidades de se destacar e ter seus objetivos alcançados quando em comparação aos demais (Carvalho, Castro, Rocha Jr, Bodini, \& Carvalho, 2009).

No caso da EP, campo que converge com as áreas administrativa e econômica, uma formação plural, generalista e multidisciplinar capacita o engenheiro de produção para atuar em distintos setores produtivos, como o de bens e serviços, por torná-lo um profissional flexível e adaptável (Faria \& Souza Jr., 2007).

A contabilidade, definida por Marion (2009) como sendo um instrumento que fornece o máximo de informações úteis para a tomada de decisões dentro e fora da empresa, é relevante também para outros cursos, conforme explicitado por Etter, Burmeister e Elder (2001), os quais afirmam que as disciplinas introdutórias à Ciência Contábil podem auxiliar os alunos dos cursos a lidarem no futuro com negócios em geral e a tomarem suas decisões de forma mais segura. Ainda mais próxima da realidade da EP, a Contabilidade Gerencial é destacada por Iudícibus (1995) como uma área voltada exclusivamente à administração da entidade, suprindo informações que auxiliem de maneira efetiva o modelo de negócio da mesma empresa, o que pode agregar à formação do engenheiro de produção com uma base teórica e prática no meio em que este atua, ainda que com roupagem distinta.

No aspecto legal, as matrizes curriculares para os cursos de Engenharia, abarcando a EP, são norteadas pela Resolução CNE/CES 11, de 11 de março de 2002 (CNE, 2002), vigente, e pela Resolução 2, de 24 de abril de 2019 (ABMES, 2019), que irá vigorar a partir de 2022, onde são apontadas as diretrizes curriculares nacionais para os cursos de graduação em Engenharia, integrando, dentre outros saberes, aspectos relacionados à Administração e à Economia, sendo as disciplinas contábeis consideradas pelas Instituições de Ensino como pertencentes à tal seara.Apesar da rele- 
vância da contabilidade para outras áreas, como a EP, não foram encontradas pesquisas nas quais tenham sido analisadas as práticas de ensino de disciplinas contábeis para o curso de EP ou, ainda, a percepção dos docentes de tal processo de ensino-aprendizagem em EP.

Na pesquisa realizada por Ben e Kliemann Neto (2016), os autores elaboraram uma proposta de conteúdos mínimos de Contabilidade Gerencial para o curso de EP oferecido por uma instituição federal localizado no sul do Brasil, tendo sido tal proposta validada e adicionada como um disciplina do curso.

Com relação a estudos que avaliaram a percepção de discentes sobre o ensino contábil em outros âmbitos, como os realizados por Borges e Mafra (2013) e Raimundini, Bianchi, Santos, Fávero e Schmidt (2009), foi apontado que os discentes de outros cursos, embora considerem as disciplinas introdutórias de contabilidade como relativamente simples, mostram insatisfação para com as metodologias utilizadas pelos professores de Ciências Contábeis, acarretando em desestímulo com relação à contabilidade.

Por outro lado, pesquisas que analisaram a percepção de docentes acerca do ensino de contabilidade em outros cursos, como realizada por Borges e Mafra (2013), demonstram que estes entendem que o ensino deve ser focado em análise e interpretação dos relatórios contábeis, e não necessariamente como fazê-los, além da dificuldade de atrair a atenção e interesses dos discentes para com as disciplinas contábeis.

\subsection{O Ensino Contábil e a Interdisciplinaridade}

O ensino e desenvolvimento contábil no Brasil ocorreu somente após 1808, com a chegada da família real, se desenvolveu ao longo do século XIX com a revolução industrial e sofreu forte influência italiana (Coelho, 2007). Porém, a partir da década de 60, a orientação didática no ensino da contabilidade mudou em função da introdução de novos métodos, tendo estes forte influência da escola norte americana (Schmidt, 2002).

Em 1996, com a aprovação da Lei no 9.394 - Lei das Diretrizes e Bases da Educação Nacional - (Brasil, 1996), promoveu-se significantes alterações no ensino superior no Brasil. Segundo afirmam Araújo, Miranda e Pereira (2017), houve ampliação das vagas nos ensinos público e privado, surgimento de novas modalidades, como o ensino a distância, além da constituição de mecanismos de regulamentação da qualidade do ensino, com o intuito de avaliar e acompanhar as políticas educacionais.

Vale destacar o advento das novas diretrizes curriculares nacionais para os cursos de contabilidade, através da Resolução 10/2004 (CNE, 2004), na qual propugnou-se a formação de contadores dotados de competências profissionais e que reflitam acerca da heterogeneidade das demandas sociais (Peleias, Silva, Segretti \& Chirotto, 2007). De igual modo, a Associação Brasileira de Engenharia de Produção (ABEPRO, 2008) definiu para o curso de Engenharia de Produção a disciplina de gestão de custos, que possui em seu conteúdo noções de contabilidade, análise das demonstrações contábeis, classificação de custos, entre outras.

Crispim e Crispim (2012) destacam a importância da disciplina de contabilidade ao curso de administração, visto ser fundamental sua compreensão no apoio à tomada de decisão, o que nos leva a um panorama de interdisciplinaridade. A interdisciplinaridade, quando envolvida em outras áreas, tem o objetivo de estimular uma interação entre aluno, professor e a rotina profissional (Bonatto, Barros, Gemeli, Lopes, \& Frison, 2012). Para O’Dwyer e Unerman (2014), o incentivo para a interdisciplinaridade em alguns círculos acadêmicos baseia-se na crença de que a interdisciplinaridade ajudará os pesquisadores a desenvolverem novas ideias convincentes.

A reflexão sobre a interdisciplinaridade tem origem no começo do século $X X$, quando um dos primeiros estudiosos a estruturar uma concepção de trabalho interdisciplinar foi o francês Ge- 
orges Gusdorf, valendo-se da criação de uma equipe de especialistas direcionada para a pesquisa interdisciplinar nas ciências humanas (Aires, 2011).

Para Fazenda (2011), a principal premissa para a concretização da interdisciplinaridade é o aprimoramento da sensibilidade. Para O'Dwyer e Unerman (2014), cada estudo individual mobiliza mais de uma teoria informadora (de mais de uma escola de pensamento). Essta síntese inovadora de teorias informativas pode então ser desenhada para dar sentido a um problema de pesquisa, usando contextos teóricos novos ou revisados de uma maneira que ajude a fornecer outros insights (O’Dwyer \& Unerman, 2014).

A interdisciplinaridade então se mostra como a união entre a percepção das disciplinas nos mais diversos campos de estudo (Bonatto et al., 2012). Para Aires (2011), há diferentes motivações que podem ser pontuadas para a interdisciplinaridade, a depender da necessidade de seu agente: aos estudantes, vê-se a necessidade de melhor nortear seus estudos, com economia de tempo, melhor adequação ao emprego e formação de pensamentos mais amplos; aos pesquisadores, professores e academia como um todo, essas motivações estão relacionadas à necessidade de buscar resultados para o constante aperfeiçoamento, de fomentar as pesquisas entre as várias áreas de estudos e de expandir os campos do saber.

A interdisciplinaridade, para Fazenda (2011), vem sendo usada como solução para os danos causados pela segregação do saber, com o intuito de realizar a manutenção da plenitude do pensamento, na forma de uma mudança de reflexão, passando-se de um conceito fragmentado para um conceito unitário. Nessa perspectiva, "o conhecimento pessoal anula-se diante do saber universal" (Fazenda, 2011, p. 11).

\section{PROCEDIMENTOS METODOLÓGICOS}

Para responder ao objetivo proposto, desenvolveu-se uma pesquisa de abordagem qualitativa. Consoante Collis e Hussey (2005), na pesquisa qualitativa busca-se identificar e mensurar questões subjetivas, como opiniões e percepções, a fim de se chegar a um melhor entendimento sobre atividades sociais e humanas. No que tange aos objetivos do presente estudo, o mesmo é classificado como de cunho exploratório, a fim de proporcionar maior conhecimento através do problema e torná-lo mais explícito, conforme leciona Gil (2007).

Com relação à técnica de coleta de dados utilizada, optou-se pela entrevista semiestruturada. Triviños (1987) argumenta que esse tipo de entrevista é caracterizado pela adoção de questionamentos básicos, apoiados em teorias e hipóteses e que, em seguida, oferece amplo campo de interrogativas, frutos de novas hipóteses que vão surgindo à medida que se recebem as respostas do informante; além de proporcionar todas as perspectivas possíveis para que o informante dê liberdade necessária ao enriquecimento da investigação. Os sujeitos da pesquisa são os quatro docentes de disciplinas contábeis que atuavam no curso de graduação em EP da instituição sob análise, no período em que os dados foram coletados primeiro semestre de 2018, por meio de entrevistas semiestruturadas realizadas de forma presencial, gravadas e transcritas na íntegra. Ainda acerca dos respondentes, todos atuam há pelo menos 10 anos na docência e por igual período no curso de EP; ainda, dois possuem formação em Economia, um em Ciências Contábeis e um em Administração de Empresas.

Com relação à análise dos dados, utilizou-se a técnica de análise de conteúdo, definida por Bardin (2009) como um conjunto de técnicas de análise das comunicações que visam obter, por meio de métodos sistemáticos e objetivos de descrições das mensagens, indicadores que permitam inferir conhecimentos relativos à produção de tais mensagens. Ainda segundo a mesma autora, há três grandes métodos de análise de conteúdo, sendo eles: análise temática ou categorial, análise formal e análise estrutural. 
Na presente pesquisa empregou-se a análise temática, a qual, consoante Bardin (2009), visa revelar as avaliações dos locutores acerca de um tema a partir do exame de certos elementos que compõem o discurso, como a frequências dos temas, avaliação de juízos, dentre outros. No que tange sua operação, a análise temática de conteúdo consiste nas seguintes etapas: pré-análise, onde é realizada a transcrição dos áudios e leitura flutuante das transcrições; exploração do material, no qual são realizadas as categorizações; e tratamento dos dados, consistindo na interpretação dos dados empíricos obtidos e o marco teórico utilizado (Minayo, 2010).

No que tange à exploração do material, Bardin (2009) declara que as categorias podem ser criadas a priori, ou seja, com base na teoria, ou a posteriori, a partir da análise dos dados obtidos. Na presente pesquisa optou-se pela categorização a posteriori, seguindo sugestão de Mendes (2007), a qual defende que a categorização deve ser sempre criada com base nos conteúdos verbalizados e com certo refinamento gramatical. Após audição e leitura sistemática das entrevistas realizadas, emergiram as seguintes categorias para fins de análise dos dados obtidos com as entrevistas: facilidades e dificuldades no processo de ensino de disciplinas contábeis; métodos de ensinos empregados; e interdisciplinaridade e percepção dos docentes sobre a relevância da contabilidade.

Ademais, utilizou-se o software QSR NVIVO 11®, com objetivo de apontamento de pontos semelhantes e divergentes entre as respostas concedidas pelos entrevistados, assim como na estruturação das categorias utilizadas.

Para a preparação das perguntas a serem utilizadas nas entrevistas, após a realização de préteste com dois professores de disciplinas contábeis em IES diferentes da pesquisada no presente estudo, elaborou-se as assertivas descritas no Quadro 1, as quais compuseram a categorização detalhada nos resultados da pesquisa.

Quadro 1 - Roteiro de entrevista

\begin{tabular}{|l|l|}
\hline Pergunta 1 & $\begin{array}{l}\text { Em sua opinião, quais são as dificuldades de ministrar disciplinas contábeis no curso de Engenharia de } \\
\text { Produção? }\end{array}$ \\
\hline Pergunta 2 & $\begin{array}{l}\text { Da mesma forma, quais são as facilidades de ministrar disciplinas contábeis no curso de Engenharia de } \\
\text { Produção? }\end{array}$ \\
\hline Pergunta 3 & $\begin{array}{l}\text { Em seu entendimento, a carga-horária de disciplinas contábeis no curso de Engenharia de Produção é } \\
\text { suficiente para o futuro engenheiro de produção lidar com as exigências do mercado de trabalho? }\end{array}$ \\
\hline Pergunta 4 & $\begin{array}{l}\text { Em sua opinião, há distinção entre o perfil de discentes de Engenharia de Produção e Ciências Contá- } \\
\text { beis? Caso sim, de que forma isso influencia no ensino/aprendizado de disciplinas contábeis? }\end{array}$ \\
\hline Pergunta 5: & $\begin{array}{l}\text { Na sua percepção, há diferenças entre a utilização de métodos de ensino para o curso de Ciências } \\
\text { Contábeis e Engenharia de Produção? Se sim, qual(is) o(a) Sr.(a) destaca? }\end{array}$ \\
\hline Pergunta 6: & $\begin{array}{l}\text { No caso de resposta afirmativa à questão anterior, percebe alguma metodologia que possa agregar no } \\
\text { ensino contábil? }\end{array}$ \\
\hline Pergunta 7 & $\begin{array}{l}\text { Na sua percepção, qual importância da interdisciplinariedade, mais precisamente, através da } \\
\text { disciplina que o(a) Sr(a) leciona, para o curso de graduação em Engenharia de Produção? }\end{array}$ \\
\hline Pergunta 8 & $\begin{array}{l}\text { Existe um elevado grau de evasão (quando se trata de disciplina eletiva) e/ou baixo rendimento na } \\
\text { disciplina que o Sr.(a) leciona para o curso de graduação em Engenharia de Produção? Se sim, quais as } \\
\text { prováveis causas? }\end{array}$ \\
\hline Percebe que os discentes de Engenharia de Produção compreendem a relevância de disciplinas contá- \\
beis para a formação do engenheiro de produção? Por quê?
\end{tabular}

Fonte: elaborado pelos autores.

A partir da inserção das assertivas no roteiro de entrevista desta pesquisa, explicitadas no Quadro 1 e elaborada por estes autores, buscou-se captar a percepção dos sujeitos da pesquisa acerca de aspectos relacionados ao processo de ensino-aprendizagem de disciplinas contábeis no âmbito do curso de graduação em EP, como facilidades e dificuldades em tal processo, importância da interdisciplinaridade, evasão de tais disciplinas, dentre outros aspectos. 


\section{RESULTADOS}

Conforme descrito no capítulo anterior, referente à metodologia de pesquisa utilizada, foram realizadas entrevistas semiestruturadas com docentes que ministram disciplinas contábeis na instituição sob análise, a fim de avaliar a percepção desses acerca do ensino de contabilidade para discentes do curso de EP. Nas subseções a seguir serão abordadas as percepções dos docentes acerca do assunto, com base nas categorias que emergiram neste trabalho.

\subsection{Facilidades e Dificuldades no Processo de Ensino de Disciplinas Contábeis}

A primeira categoria emergida é composta pelas percepções de docentes sobre questões facilitadores e dificultadoras presentes no ensino de disciplinas de contabilidade para os discentes do curso de graduação em EP. Foi apontada que uma questão que pode ser entendida como sendo dificultosa para o ensino de contabilidade é o tempo reduzido das disciplinas contábeis perante o total de horas do curso de graduação em Engenharia de Produção, sendo esta questão indicada por dois entrevistados, explicitado pelo respondente 1:

"No meu entendimento, no caso desta instituição, eu acho que ainda precisa de uma disciplina de 60 horas. Atualmente eu tenho uma carga de três tempos em contabilidade gerencial, três tempos em contabilidade de custos e uma optativa de finanças. Só tem isso em contabilidade no curso inteiro, o que representa um total de nove horas no curso. No meu entendimento é pouco. A gente vai tentar ver se consegue ou não incluir uma carga horária maior. Eu acho pouco." (Respondente 1)

Possui entendimento distinto o respondente 3, que afirma "entendo ser suficiente num curso que possui outras áreas a serem ministradas com foco na habilitação profissional da Engenharia de Produção"; ressaltando que, em seu entendimento, a quantidade de disciplinas e hora-aula atuais de contabilidade no curso de EP está adequada, visto que maior ênfase deve ser dada às disciplinas da própria área.

Com relação às facilidades de ensino percebidas pelos entrevistados, há consenso acerca do fato de os discentes do curso de EP terem facilidade para o entendimento de operações matemáticas necessárias, inclusive em comparação aos alunos de Ciências Contábeis, consoante percepção do respondente 1 :

"A facilidade vem do quesito que eles têm uma queda, um perfil mais voltado para matemática, então isso facilita um pouco o entendimento na área de Finanças, que engloba um pouco de estatística né, então quando eu dou aula de Finanças para eles é fácil fazê-los entender e compreender todas as fórmulas do que para o aluno de Ciências Contábeis." (Respondente 1)

Assim, denota-se que os docentes entrevistados destacam como dificuldades relevantes para o ensino de contabilidade para o curso de EP a carga-horária reduzida dedicada a essas disciplinas. Contudo, o perfil do futuro engenheiro de produção, somado às exigências matemáticas do curso, resulta em discentes que possuem mais facilidade em lidar com questões matemáticas, inclusive àquelas inseridas na seara contábil.

\subsection{Os Métodos de Ensino Empregados no Ensino Contábil na Engenharia de Produção}

Na categoria emergida em voga aborda-se os principais métodos de ensino empregados pelos docentes, identificando-se, ainda, a distinção entre o perfil de discentes de EP e Ciências Contábeis e a forma como esta distinção influencia no processo de ensino-aprendizado nas disciplinas de contabilidade. 
Todos os respondentes afirmaram que são perfis distintos de discentes e finalidades diferenciadas, visto que enquanto os discentes de EP são mais analíticos e voltados para a tomada de decisão, nos cursos de contabilidade o discente não se vê usando a contabilidade para fins gerenciais, pois são mais voltados a atuar profissionalmente com regras e burocracias impostas pelo poder público.

Adicionalmente, os discentes de EP têm maior facilidade com temas que envolvem cálculos, o que facilita o aprendizado em questões da área de finanças, ao passo que discentes de cursos de Ciências Contábeis apresentam maior dificuldade, por não possuírem uma base consistente em assuntos que envolvam cálculos, refletindo no ensino-aprendizado destes.

Tais dificuldades são corroboradas por estudos anteriores, como o realizado por Panucci Filho (2010), que ao investigar junto aos discentes de Ciências Contábeis as dificuldades encontradas no aprendizado, ressaltou que os poucos conhecimentos em matemática e cálculo prejudicam o rendimento dos discentes durante o curso.

No tocante a percepção das diferenças entre a utilização dos métodos de ensino para a graduação de EP e Ciências Contábeis, destaca-se o aprofundamento dos temas pertinentes à contabilidade, visto que ao contrário do discente de Ciências Contábeis, o qual necessita aprender detalhadamente como produzir as informações contábeis, o discente de EP precisa saber da utilidade daquela informação para a tomada de decisão.

"Enquanto que ensinamos os discentes em Ciências Contábeis a atuar individualmente para atender aos usuários, ensinamos os discentes de Engenharia de Produção a trabalharem em equipes interdisciplinares e multidisciplinares, dado a subjetividade no processo de tomada de decisão." (Respondente 3).

Tal afirmativa encontra respaldo no estudo de Ben e Kliemann Neto (2016), tendo esses autores concluído que o papel do engenheiro de produção vai além de gerenciar o processo produtivo das organizações, pois também pode contribuir diretamente para a maximização dos resultados da empresa, oriundo de análises tributárias ou na adequação do nível de estoques, o que interfere diretamente no resultado apresentado, sendo necessário o domínio dessas análises para a tomada de decisão.

Partindo do pressuposto de que há diferenças na utilização dos métodos de ensino para a graduação de EP e Ciências Contábeis, no tocante a identificação de uma metodologia que possa agregar no ensino contábil, os respondentes identificaram que apesar de ser trabalhado um nível de conhecimento mais superficial, ainda assim é necessária a realização de exercícios de contabilidade para a fixação do conhecimento, o investimento em tecnologias da informação e da comunicação e a utilização de ferramentas como softwares. Além disso, os respondentes afirmam que não identificaram nenhum outro método revolucionário para ministrar contabilidade dentro da EP, conforme explicitado pelo respondente 2 .

\footnotetext{
“Não adianta, contabilidade não dá para aprender sem fazer exercício, não consigo ver uma coisa muito... uma metodologia revolucionária na contabilidade, sabe. Eu tentei trabalhar com jogos durante um tempo, não funcionou; tentei trabalhar com artigos científicos, não funcionou; o "bê-á-bá" é livro e exercício, livro e exercício." (Respondente 2).
}

Percepção distinta possui o respondente 4, o qual entende que, embora a realização de exercícios seja fundamental, o que está em consonância com o respondente 2, a utilização de outras técnicas de ensino de "cunho" ativo também são relevantes. 
[...] "eu tento dividir: seminários, atividades em laboratório para o aluno conhecer fontes de dados do Ibovespa por exemplo, por onde ele pode ter acesso ao Balanço Patrimonial, DRE; também em artigos científicos a gente trabalha, prepara, não o desenvolvimento, mas a leitura, eu os utilizo na forma de seminários. Também faço as listas de exercícios... acho que são fundamentais, listas de exercício tem que ter, principalmente em uma disciplina como essas, de contabilidade." (Respondente 4)

Dessa forma, a diferença de percepção dos sujeitos da pesquisa acerca das técnicas de ensino utilizadas coaduna com os achados de Rezende, Silva, Prado e Bernardino Neto (2014, p. 11), os quais afirmam que "não existe um método de ensino acabado ou definido como melhor. A implementação de uma mudança no ensino exige o estudo investigativo e avaliação constante de falhas e acertos, a fim de realizar melhorias tanto quanto for possível."

\subsection{O Papel da Interdisciplinaridade na Percepção Quanto à Relevância do Ensino Contábil para a Engenharia De Produção}

A percepção quanto à inserção de disciplinas contábeis no curso de graduação em EP, conforme abordado nos aspectos sobre interdisciplinaridade, mostrou-se evidenciada na formação de um profissional completo, dando-lhe uma visão ampla não só daquilo que é atribuição de um engenheiro de produção, como também a compreensão sobre o processo produtivo no qual ele está inserido.

"No caso da minha disciplina, ajuda a evidenciar bastante o que eles têm que entender de custos em Engenharia de Produção, o que eles têm que saber da importância dos relatórios contábeis, ou seja, do resultado que a empresa produz; e em finanças, para ele entender que qualquer mudança que ele faz na produção vai impactar o resultado da empresa, e isso está tudo ligado." (Respondente 1)

Algumas das disciplinas de contabilidade ministradas pelos sujeitos da pesquisa não fazem parte da grade obrigatória do curso de graduação na instituição em voga, sendo sua matrícula facultativa. A percepção dos professores entrevistados, quanto ao interesse na contabilidade por parte dos alunos, manifestou-se em opiniões divergentes.

Foram apontadas percepções positivas acerca da procura muitas vezes ser maior que a oferta de vagas, havendo a necessidade da ampliação do número de vagas, visando uma distribuição melhor dos alunos nas disciplinas eletivas. As percepções negativas ficaram por conta do desinteresse de alguns alunos que, inicialmente, não dão a devida importância à disciplina, por considerála de menor relevância.

"Geralmente após a primeira avaliação, registro abandonos e trancamentos na disciplina. As possíveis causas estão relacionadas à cultura dos discentes em relação à importância da disciplina no curso e falta de hábito de estudo, pois reclamam muito que as resoluções das questões são grandes." (Respondente 3)

Na opinião dos docentes entrevistados, essa primeira impressão negativa é creditada pelo entendimento, por parte de alguns alunos, que disciplinas contábeis são mais apropriadas aos administradores. Essa impressão é modificada quando do reconhecimento da relevância da contabilidade na EP, seja pela necessidade de evoluir dentro do próprio curso, pela identificação da aplicação na prática laboral, ou mesmo pela explanação por parte dos docentes acerca de tal relevância. 
"Eles só vão perceber isso, ou depois que já fizeram as disciplinas, quando são solicitados nas outras, ou quando vão para o mercado de trabalho. Inicialmente eles não entendem o que estão fazendo ali, por quais razões têm as disciplinas de contabilidade." (Respondente 2)

Tal perspectiva, apontada pelos sujeitos da pesquisa, coaduna com os resultados obtidos no estudo realizado por Borges e Mafra (2016), no qual docentes que ministram disciplinas contábeis para não-contadores apontam que encontram dificuldade em descobrir meios para suscitar interesse dos discentes, de forma que estes percebam a relevância das disciplinas contábeis para sua formação.

Ainda, vale destacar que, dentre os estudos sobre a interdisciplinaridade voltada para a EP, percebe-se que "a interdisciplinaridade fornece ao engenheiro um amadurecimento, possibilitando um leque de conhecimentos" (Silva, Silva, Queiroz, Alencar, \& Barros, 2016, p. 10).

Para Fazenda (2015), na perspectiva educativa, os conhecimentos acadêmicos necessitam de uma estrutura diferente da estrutura que constituem cada curso, havendo a preocupação com o processo de aprendizagem respeitando a compreensão do aluno e sua integração, apoiando-se em noções, habilidades e técnicas adequadas.

\section{CONCLUSÃO}

O presente estudo teve como objetivo avaliar as percepções dos docentes de contabilidade no curso de graduação em Engenharia de Produção, a fim de identificar as variáveis que impactam no processo de ensino-aprendizagem do futuro engenheiro de produção, especialmente no que tange disciplinas contábeis.

Considerando-se o objetivo desta pesquisa e a metodologia utilizada, a percepção dos docentes de disciplinas contábeis acerca do ensino de contabilidade para discentes do curso de EP mostrou-se subdividida em 3 categorias, a partir das quais possibilitou-se analisar as percepções dos docentes sobre o processo de ensino-aprendizagem do discente do curso de EP e como é tratada a relevância do ensino das disciplinas contábeis.

Acerca do processo de ensino, foi apontado na pesquisa como um fator de dificuldade a carga-horária reduzida de disciplinas contábeis, embora este aspecto seja justificado pelo curso possuir outras áreas a serem ministradas, especialmente com foco na habilitação profissional da EP.

Com relação à percepção sobre facilidades no processo de ensino, os docentes entrevistados ressaltam uma das características dos discentes de EP em relação aos de contabilidade, visto que aqueles possuem inclinação para o entendimento de operações matemáticas e estatísticas, incluindo as inseridas no ambiente contábil, o que facilita o processo de ensino-aprendizagem da ciência contábil.

Acerca dos métodos de ensino empregados, os respondentes apontam que ao contrário do curso de Ciências Contábeis, no qual se requer maior aprofundamento no aspecto financeiro contábil, na graduação em EP, a contabilidade é tratada mais superficialmente, visto que o objetivo se concentra em compreender a utilidade das informações contábeis a fim de contribuir para o direcionamento de melhores resultados da empresa, ou seja, com aspecto gerencial; ainda, o método tradicional de ensino se mostra o mais utilizado e indicado pelos sujeitos respondentes da pesquisa.

No tocante à interdisciplinaridade, mais especificamente com relação ao ensino de contabilidade no curso de graduação em EP, denota-se que, embora os discentes tenham dificuldade em entender sua importância, esta é relevante para uma formação mais completa e robusta do futuro engenheiro de produção, por possibilitar o preparo dos discentes com relação a uma visão ampla 
no que tange a gestão das organizações. Ainda, denota-se que os conhecimentos em contabilidade são uma ferramenta essencial para a tomada de decisão que esse futuro profissional necessitará executar ao longo de sua trajetória profissional.

Nesse sentido, nesta pesquisa expôs-se que embora os docentes que ministram disciplinas contábeis no âmbito do curso de EP destaquem a importância da presença de tais disciplinas no curso sob análise, existem dificuldades relacionadas ao processo de ensino-aprendizagem, especialmente as alusivas à relação dos discentes para com as disciplinas contábeis e, ainda, à matriz curricular do curso. Assim, entende-se ser relevante que a perspectiva de tais docentes seja levada em consideração por parte das instituições de ensino que oferecem a graduação em EP, a fim de que tal processo de ensino-aprendizagem possa ser aperfeiçoado, resultando em um melhor aprendizado dos aspectos contábeis pertinentes à formação dos discentes do curso.

O presente estudo não visa esgotar as pesquisas acerca do ensino de disciplinas contábeis em outras áreas, tampouco delimitar o entendimento sobre o ensino da contabilidade no curso de graduação em EP. As percepções aqui apontadas, assim como a literatura consultada e utilizada, sugerem a relevância da pesquisa contábil acerca do ensino de contabilidade no contexto acadêmico como um todo - não ficando restrita apenas ao ensino no curso de graduação em Ciências Contábeis -, de forma a fomentar pesquisas futuras que discorram sobre metodologias e abordagens mais propícias a cada área do saber, com a finalidade de atender o vasto campo de aplicação da contabilidade.

As limitações da pesquisa consistem no pequeno quantitativo de docentes que ministram disciplinas contábeis no curso de EP na instituição sob análise e, portanto, na quantidade reduzida de sujeitos da pesquisa entrevistados. Como sugestão para futuras pesquisas, sugere-se captar a percepção dos discentes de EP, a fim de entender suas dificuldades e facilidades no processo de aprendizado de disciplinas contábeis, bem como replicar o presente estudo para outras instituições de ensino, sejam públicas ou privadas.

\section{REFERÊNCIAS}

Aires, J. A. (2011). Integração Curricular e Interdisciplinaridade: sinônimos?. Educação E Realidade, $36(1), 215-230$.

AlHashim, D. D., \& Weiss, E. J. (2004). Recent developments in accounting education and the future of the AICPA 150-hour requirement. International Journal of Commerce and Management, 14(1), 19-27.

Araújo, T. S., Miranda, G. J., \& Pereira, J. M. (2017). Satisfaction among accounting professors in Brazil. Revista Contabilidade E Finanças, 28(74), 264-281.

Associação Brasileira de Engenharia de Produção - ABEPRO. (2008). Áreas e subáreas de Engenharia de Produção. Recuperado de http://www.abepro.org.br/interna.asp?p= 399 \&m =424 $\& s=1 \& c=362$

Associação Brasileira de Mantenedores de Ensino Superior - ABMES. (2019). Resolução nº 2, de 24 de abril de 2019. Institui as diretrizes curriculares nacionais do curso de graduação em engenharia. Recuperado de http://abmes.org.br/arquivos/legislacoes/Resolucao-CNE-CES-0022019-04-24.pdf

Bardin, L. (2009). Análise de conteúdo Lisboa: Edições 70. 
Ben, F.; Kliemann Neto, F. J. (2016). Organização de conteúdos mínimos de contabilidade gerencial para cursos de graduação em Engenharia de Produção. XXXVI Encontro Nacional de Engenharia de Produção. 1-16.

Bonatto, A., Barros, C. R., Gemeli, R. A., Lopes, T. B., \& Frison, M. D. (2012). Interdisciplinaridade no ambiente escolar. Seminário de Pesquisa em Educação da Região Sul. 1-12.

Borges, G. de F., \& Mafra, F. L. N. (2013). Ensino de contabilidade em cursos de graduação em administração: Uma análise da percepção docente e discente em instituições de ensino superior de Minas Gerais. RACE-Revista de Administração, Contabilidade e Economia, 12(3), 191-226.

Borges, G. de F., \& Mafra, F. L. N. (2016). Atitude discente em relação ao ensino de contabilidade em cursos de administração: uma análise estatística. Revista Mineira de Contabilidade, 4(52), 63-72.

Brasil. (1996). Lei n. 9.394, de 20 de dezembro de 1996. Estabelece as diretrizes e bases da educação nacional. Recuperado de http://www.planalto.gov.br/ccivil_03/leis/19394.htm

Carvalho, F. C. A., Castro, J. E. E., Rocha Jr, W. F., Bodini, V. L., \& Carvalho, T. C. A. (2009). A interdisciplinaridade no ensino da engenharia: A internet como ferramenta. Revista Digital de Biblioteconomia e Ciência da Informação. 1-7.

Coelho, C. U. F. (2007). Reflexões Sobre O Ensino de Contabilidade: Aspectos Culturais E Metodológicos. Boletin Técnico SENAC. 62-75.

Collis, J., \& Hussey, R. (2005). Pesquisa em administração: um guia prático para alunos de graduação e pósgraduação. (2a ed.). Porto Alegre: Bookman.

Conselho Nacional de Educação - CNE. (2004). Resolução CNE/CES 10, de 16 de dezembro de 2004. Institui as diretrizes curriculares nacionais para o curso de graduação em Ciências Contábeis, bacharelado, e dá outras providências. Recuperado de http://portal.mec.gov.br/cne/arquivos/pdf/rces10_04.pdf

Conselho Nacional de Educação - CNE. (2002). Resolução CNE/CES 11, de 11 de março de 2002. Institui diretrizes curriculares nacionais do curso de graduação em Engenharia. Recuperado de http://portal.mec.gov.br/cne/arquivos/pdf/CES112002.pdf

Crispim, G., \& Crispim, G. (2012). O Ensino Da Contabilidade No Curso De Administração De Empresa: A Percepção Do Corpo Discente Das Disciplinas De Contabilidade Na Sua Formação Acadêmica. Advances in Scientific and Applied Accounting 5(1), 131-55.

Cruz, N. V. S., Batista, A. B., Andrade, C. M., \& Bruni, A. L. (2013). O Ensino da Contabilidade vinculada à área de Custos e Gestão no Curso de Ciências Contábeis no Nordeste Brasileiro: uma análise da adequação da proposta de conteúdos abordados pelas IES às diretrizes do CFC (2009) e do ISAR/UNCTAD/ONU. In Anais do Congresso Brasileiro de Custos, Uberlândia, MG, Brasil, 13. Recuperado de https://anaiscbc.emnuvens.com.br/anais/article/view/133

Etter, E. R., Burmeister, S. L., \& Elder, R. J. (2001). Improving student performance and retention via supplemental instruction. Journal of Accounting Education, 18(4), 355-368. 
Faria, A. F., \& Souza Jr., A. C. R. (2007). Propostas de melhoria do projeto pedagógico através do acompanhamento dos egressos. Gepros: Gestão da Produção, Operações e Sistemas, 2(1), 33-41.

Fazenda, I. C. A. (2015). Interdisciplinaridade: didática e prática de ensino. Interdisciplinaridade. Revista do Grupo de Estudos e Pesquisa em Interdisciplinaridade. (6), 9-17.

Fazenda, I. C. A. (2011). Integração e interdisciplinaridade no ensino brasileiro. (6a ed.). São Paulo: Edições Loyola.

Gil, A. C. (2007). Métodos e técnicas de pesquisa social. (6 $6^{\underline{a}}$ ed.). São Paulo: Atlas.

Iudícibus, S. (1995). Contabilidade Gerencial. (5a ed.). São Paulo: Atlas.

Iudícibus, S., \& Marion, J. C. (2011). Curso de contabilidade para não contadores. (7a ed.). São Paulo: Atlas.

Kraemer, M. E. P. (2005). Reflexões sobre o ensino da contabilidade. Revista Brasileira de Contabilidade, (153), 64-79.

Leal, D. T. B., \& Cornachione Jr, E. (2006). A aula expositiva no ensino da contabilidade. Contabilidade vista E revista, 17(3), 91-113.

Marion, J. C. (2009). Contabilidade Básica. São Paulo: Atlas.

Mendes, A. M. (2007). Psicodinâmica do trabalho: teoria, método e pesquisa. São Paulo: Casa do Psicólogo.

Minayo, M. C. S. (2010). Introdução. In: Minayo, M. C. S., Assis, S. G., \& Souza, E. R. (Org). Avaliação por triangulação de métodos: abordagem de programas sociais. Rio de Janeiro: Fiocruz.

Nascimento, Z. M de A. (2009). Formação e inserção profissional de engenheiros: um olhar materialista histórico. Educere et Educare, 4(8), 181-196.

O'Dwyer, B., \& Unerman, J. (2014). Realizing the potential of interdisciplinarity in accounting research. Accounting, Auditing \& Accountability Journal, 27(8), 1227-1232.

Panucci Filho, L. (2010). Dificuldades e perspectivas dos estudantes de ciências contábeis da Universidade Federal do Paraná segundo o perfil socio educacional (Dissertação de mestrado). Universidade Federal do Paraná, Curitiba, PR, Brasil.

Peleias, I. R., Silva G. P., Segreti, J. B. \& Chirotto, A.R. (2007). Evolução Do Ensino Da Contabilidade No Brasil: Uma Análise Histórica. Revista Contabilidade E Finanças 18(3), 19-32.

Raimundini, S. L., Bianchi, M., Santos, N. de A., Fávero, L. P. L., \& Schmidt, P. (2009). Percepções sobre o ensino da contabilidade introdutória para não contadores: a perspectiva dos discentes das universidades federais do estado do Rio Grande do Sul. Revista de Educação e Pesquisa em Contabilidade, 3(3), 85-105. 
Rezende, L. A.; Silva, H. F.; Prado, C. F. do; Bernardino Neto, M. (2014). Análise da percepção de graduandos em Engenharia quanto à implantação de metodologias de aprendizagem ativa. XI Simpósio de Excelência em Gestão e Tecnologia.

Santos, F. C. A. (2003). Potencialidades de mudanças na graduação em Engenharia de Produção geradas pelas diretrizes curriculares. Revista Produção, 13(1), 26-39.

Schmidt, P. (2002). História Do Pensamento Contábil. Porto Alegre: Bookman.

Silva, L. R., Silva, M. W. V., Queiroz, A. B. S. V., Alencar, L. M. B., \& Barros, I. F. (2016). Uma revisão sobre a evolução dos cursos de Engenharia de Produção no Brasil. XXXVI Encontro Nacional de Engenharia de Produção. 1-13.

Silva, U. B., \& Bruni, A. L. (2017). O Que me Ensina a Ensinar? Um Estudo Sobre Fatores Explicativos das Práticas Pedagógicas no Ensino de Contabilidade. Revista de Educação e Pesquisa em Contabilidade - REPeC, 11(2), 214-230.

Tan, L. M., \& Laswad, F. (2006). Students' beliefs, attitudes and intentions to major in accounting. Accounting Education: an international journal, 15(2), 167-187.

Triviños, A. N. S. (1987). Introdução à pesquisa em ciências sociais a pesquisa qualitativa em educação. São Paulo: Atlas.

Wet, J. H., \& Van Niekerk, M. C. (2001). An innovative approach to accounting education at the first-year level. Meditari Accountancy Research, 9(1), 93-108. 